\title{
What contributes to quality of life in Parkinson's disease: a re-evaluation
}

\author{
Anette Schrag (1) , Niall Quinn
}

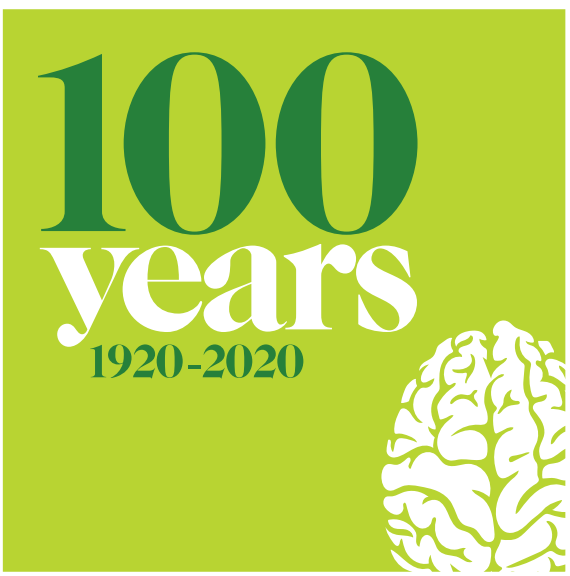

Taking the patient perspective has led to increasing recognition of the importance of depression and other non-motor features in Parkinson's disease

Twenty years ago, we published a paper examining which of the clinical features of Parkinson's disease (PD) were most closely associated with patients' self-reported health-related quality of life (HR-QoL). ${ }^{1}$ In the early 1990s, the focus of clinical management and treatment trials in PD had been the development of better management options for the motor features and complications of therapy, such as motor fluctuations and dyskinesias. The key target in clinical trials was improvement on the primary outcome measure, the Unified Parkinson's Disease Rating Scale (UPDRS). ${ }^{2}$ However, clinical assessment, and in particular clinical trials, almost entirely relied on clinicians' judgement of severity of disease and its complications. This was a reflection of lack of availability of robust measures to capture patients' own view, and probably also a different attitude in medicine and society in general, which placed greater emphasis on clinician judgement than on patients' evaluation. However, in the late 1990s, this had started changing and the development of standardised scales to assess

UCL Institute of Neurology, University College London, London, UK

Correspondence to Professor Anette Schrag, UCL Institute of Neurology, University College London, London NW3 2PF, UK; a.schrag@ucl.ac.uk
What contributes to Quality of Life in Parkinson's disease - a revaluation Authors: Anette-Eleonore Schrag, Niall Quinn

Year published: 2000

Number of times cited: 842

how patients evaluate their own health problems, so-called HR-QoL measures, had recently enabled standardised quantitative assessment of patients' views. HR-QoL scales made it possible to assess impact on patients' lives, independent from clinicians' assessments, and to incorporate other aspects of HR-QoL, such as the emotional and social impact of the disease. A HR-QoL specifically for patients with PD had been developed through careful analysis of interviews and validation in patients with $\mathrm{PD} .^{3}$ This allowed assessment of the impact of PD on patients from more than a physical, objective point of view; it also provided the opportunity to assess which aspects of the features of PD have the greatest impact from patients' perspective. However, no such studies had been published to answer this question.

In the planning of a community-based prevalence study of parkinsonism in UK, which included an in-depth characterisation of patients' clinical features, ${ }^{4}$ we therefore took the opportunity to quantitatively assess patients' own experiences using the newly developed PD-specific HR-QoL scale. In particular, we were interested in how this reflects the importance of individual features of $\mathrm{PD}$, whether motor, non-motor or medication induced, from the patients' point of view. The study was conducted in a community-based, unselected sample of patients recruited through primary care practices in and around London, many of whom were seen at home. Assessing a large number of individuals, and choosing a representative sample in the community rather than a specialist centre population, allowed us to draw conclusions applicable to the overall population of PD. We studied, for the first time, the areas of greatest impairment of HR-QoL in PD and which of the manifestations of PD impacted the most on their life from the patients' own point of view. The expectation was that the key determinant of HR-QoL would be the severity of motor function, captured in the UPDRS motor part. However, despite disease severity ranging from mild to severe, motor severity, as assessed on the UPDRS motor part, was not the main contributor to the HR-QoL as evaluated by patients.

\section{THE IMPORTANCE OF DEPRESSION}

While overall disability was an important factor, the key and overwhelmingly determining feature associated with poorer HR-QoL was the severity of depressive features, as assessed on the Beck Depression Inventory. Depression had been recognised as associated with PD, but was often considered a consequence ${ }^{5}$ although it had also been suggested as a manifestation of brain dysfunction. ${ }^{6}$ We now know that, at least in part, it is an integral feature of the disease, and is significantly more common many years before the diagnosis $^{78}$ in people with a later diagnosis of PD than in controls. However, at the time few research studies had been conducted into recognising, treating or understanding depressive features of $\mathrm{PD}$, and relatively little attention was paid to it in clinical practice. The result of our study, ${ }^{1}$ which demonstrated that depression is closely linked with how patients evaluate their own HR-QoL, over and above their physical impairment, has since been replicated multiple times in other PD populations, spanning different countries, disease stages and research methodologies. This included another study with the same aim, across different countries, published soon after our study ${ }^{9}$ and a recent study pooling data from 25 centres in 3206 patients. ${ }^{10}$ Clearly, the presence of other clinical features of PD, particularly when severe, can also be associated with reduced HR-QoL, as examined in studies in different populations (eg, tertiary care, younger age groups or later disease stage), or examining specific aspects such as fatigue, apathy or pain in more detail. ${ }^{1011}$ Their improvement, for example, of dyskinesia, can lead to an improvement of HR-QoL. ${ }^{12}$ However, depression, when measured, has uniformly been shown to be the most robust predictor 
of HR-QOL scores in virtually all studies when included in the assessment. It may be argued that those with depression are likely to rate their health worse than those who are not but, like in subsequent studies in other conditions such as multiple sclerosis where similarly strong associations between depression and HR-QoL were found ${ }^{13}$, this does not negate the importance of alleviating this symptom of PD in order to improve HR-QoL. When the ultimate aim of treatment is improvement of patients' judgement of quality life, the mechanism of this relationship matters considerably less than it does in studies assessing a 'hard' outcome such as a biomarker or clinicianrated outcome.

\section{SUBSEQUENT RESEARCH}

Research on depression in PD has proliferated since then, leading to a much greater understanding of its pathophysiology and treatment, and we now recognise this as an integral part of the symptomatology of $\mathrm{PD}$, contributed to by the early pathological changes of PD as well as psychosocial factors. Imaging studies have explored MRI and PET markers of depression in PD,${ }^{14}$ the clinical phenomenology of depression in PD has been assessed ${ }^{15} 16$ and a number of treatment trials for depression in PD have been completed. ${ }^{17}$ Depression in PD has also been suggested as a predictor of poorer outcome, ${ }^{18}$ and PD associated with depression has been considered a possible subtype of PD. ${ }^{19}{ }^{20}$ Most importantly, especially as depression may not be volunteered spontaneously, we need to recognise its importance in the management of individual patients in clinical practice, as its treatment can improve HR-QoL beyond the treatment of motor features.

\section{OTHER FACTORS}

There is no doubt that other features of PD also contribute to reduced HR-QoL. In keeping with our a priori hypothesis, the other key determining factors in our study were the degree of disability, and the presence of postural impairment, which also emerged as strong predictor of HR-QoL scores. This reflects the welldescribed morbidity, including risk of injuries, consequent fear of falling and social consequence of falls. ${ }^{21}$ Furthermore, cognitive impairment, as assessed on the Mini Mental State Examination, was also a key determining factor for reduced HR-QoL. There had been no previous studies on the relationship of cognitive impairment with HR-QoL in PD, and the importance of this relationship was not clear at the time, but has been replicated in several studies since then. ${ }^{22}$ Our study and subsequent ones in different populations have helped bring into more focus the importance of cognitive impairment, even in those who do not have dementia. Perhaps most importantly, the recognition that non-motor features, such as depression and cognitive impairment, may be more important to patients' evaluation of the impact of their disease than pure motor impairment began to shift the focus in both research and clinical practice from the improvement of motor scores towards a broader view of motor and non-motor symptoms. The assessment and treatment of unmet non-motor symptoms has become a key target in PD research, ${ }^{23}$ including in many treatment trials.

There remained a proportion of unexplained variation of HR-QoL scores. This was to be expected, given the heterogeneity of the disease and its context between individuals, the multifaceted aspects of an individual's life that contribute to their evaluation of HR-QoL, and the fact that not all features of PD could be assessed in our study. For example, impulse control disorders associated with dopamine agonists were not yet recognised and we did not specifically assess other aspects of PD such as some autonomic features in detail. Other studies later assessed a range of specific features, for example, impulse control disorders, autonomic features, fatigue or hallucinations and found them also to be associated with reduced quality of life. Although we did not assess psychosocial or healthcare-related factors, nevertheless personal factors, such as level of optimism and experiences of healthcare or how the diagnosis was communicated, have been recognised to be important additional factors. ${ }^{9}$

\section{CONCLUSION}

The key findings of our study have been replicated across different cultures and populations, with additional factors continuing to be explored. The treatment of non-motor features, in particular depressive symptoms, has become a focus of clinical management as well as a burgeoning field of research. Ultimately, it is the improvement of patients' well-being from their point of view that is the aim of any symptomatic treatment, and HR-QoL measurement, together with assessment of non-motor as well as motor features, now has its firm place in our evaluation of the severity and impact of PD in trials and clinical practice.

Funding The authors have not declared a specific grant for this research from any funding agency in the public, commercial or not-for-profit sectors.

Competing interests None declared.
Patient consent for publication Not required. Provenance and peer review Commissioned; internally peer reviewed.

(C) Author(s) (or their employer(s)) 2020. No commercial re-use. See rights and permissions. Published by BMJ.

\section{D) Check for updates}

To cite Schrag A, Quinn N. J Neurol Neurosurg Psychiatry 2020;91:563-565.

Received 31 January 2020

Accepted 5 February 2020

Published Online First 5 March 2020

J Neurol Neurosurg Psychiatry 2020;91:563-565. doi:10.1136/jnnp-2019-322379

\section{ORCID iD}

Anette Schrag http://orcid.org/0000-0002-9872-6680

\section{REFERENCES}

1 Schrag A, Jahanshahi M, Quinn N. What contributes to quality of life in patients with Parkinson's disease? J Neurol Neurosurg Psychiatry 2000;69:308-12.

2 Fahn S, Elton R, Members of the updrs Development Committee. Unified Parkinson's Disease Rating Scale. In: Fahn S, Mardsen CD, Jenner P, eds. Recent developments in Parkinson's disease volume II. Florham Park, NJ: Macmillan Health Care Information, 1987: 153-63.

3 Peto V, Jenkinson C, Fitzpatrick R. PDQ-39: a review of the development, validation and application of a Parkinson's disease quality of life questionnaire and its associated measures. J Neurol 1998;245 Suppl 1:S10-14.

4 Schrag A, Ben-Shlomo Y, Quinn NP. Cross sectional prevalence survey of idiopathic Parkinson's disease and parkinsonism in London. BMJ 2000;321:21-2.

5 Brown R, Jahanshahi M. Depression in Parkinson's disease: a psychosocial viewpoint. Adv Neurol 1995;65:61-84

6 Tandberg E, Larsen JP, Aarsland D, et al. Risk factors for depression in Parkinson disease. Arch Neurol 1997:54:625-30.

7 Schrag A, Horsfall L, Walters K, et al. Prediagnostic presentations of Parkinson's disease in primary care: a case-control study. Lancet Neurol 2015;14:57-64.

8 Ishihara L, Brayne C. A systematic review of depression and mental illness preceding Parkinson's disease. Acta Neurol Scand 2006;113:211-20.

9 The Global Parkinson's Disease Survey (GPDS) Steering Committee. Factors impacting on quality of life in Parkinson's disease: results from an international survey. Mov. Disord. 2002;17:60-7.

10 Skorvanek M, Martinez-Martin P, Kovacs N, et al. Relationship between the MDS-UPDRS and quality of life: a large multicenter study of 3206 patients. Parkinsonism Relat Disord 2018:52:83-9.

11 Rahman S, Griffin HJ, Quinn NP, et al. Quality of life in Parkinson's disease: the relative importance of the symptoms. Mov Disord 2008;23:1428-34.

12 Geraedts VJ, Feleus S, Marinus J, et al. What predicts quality of life after subthalamic deep brain stimulation in Parkinson's disease? A systematic review. Eur J Neurol 2020;27:419-428.

13 Benedict RHB, Wahlig E, Bakshi R, et al. Predicting quality of life in multiple sclerosis: accounting for physical disability, fatigue, cognition, mood disorder, personality, and behavior change. J Neuro/ SCi 2005:231:29-34.

14 Alzahrani H, Venneri A. Cognitive and neuroanatomical correlates of neuropsychiatric symptoms in Parkinson's disease: a systematic review. J Neuro/ SCi 2015;356:32-44 
15 Marsh L, McDonald WM, Cummings J, et al. Provisional diagnostic criteria for depression in Parkinson's disease: report of an NINDS/NIMH work group. Mov Disord 2006:21:148-58.

16 Brown RG, Landau S, Hindle JV, et al. Depression and anxiety related subtypes in Parkinson's disease. J Neurol Neurosurg Psychiatry 2011;82:803-9.

17 Zhuo C, Xue R, Luo L, et al. Efficacy of antidepressive medication for depression in

Parkinson disease: a network meta-analysis. Medicine 2017:96:e6698.
18 Post B, Merkus MP, de Haan RJ, et al. Prognostic factors for the progression of Parkinson's disease: a systematic review. Mov Disord 2007;22:1839-51. quiz 1988.

19 Reijnders ISAM, Ehrt U, Lousberg R, et al. The association between motor subtypes and psychopathology in Parkinson's disease. Parkinsonism Relat Disord 2009:15:379-82.

20 Henderson R, Kurlan R, Kersun JM, et al. Preliminary examination of the comorbidity of anxiety and depression in Parkinson's disease. J Neuropsychiatry Clin Neurosci 1992;4:257-64.
21 Boonstra TA, van der Kooij H, Munneke M, et al. Gait disorders and balance disturbances in Parkinson's disease: clinical update and pathophysiology. Curr Opin Neurol 2008;21:461-71.

22 Lawson RA, Yarnall AJ, Duncan GW, et al. Cognitive decline and quality of life in incident Parkinson's disease: the role of attention. Parkinsonism Relat Disord 2016;27:47-53.

23 Schapira AHV, Chaudhuri KR, Jenner P. Non-motor features of Parkinson disease. Nat Rev Neurosci 2017:18:435-50 